\title{
Editorial
}

\section{Advances and Perspectives of Supercritical Fluid Technology}

\author{
Giuseppe Caputo, ${ }^{1}$ Ignacio Gracia Fernández, ${ }^{2}$ \\ Marleny D. A. Saldaña, ${ }^{3}$ and Alessandro Galia ${ }^{4}$ \\ ${ }^{1}$ Dipartimento di Ingegneria Industriale, Università di Salerno, Salerno, 84084 Fisciano, Italy \\ ${ }^{2}$ Departamento de Ingeniería Química, Universidad de Castilla-La Mancha, 13004 Ciudad Real, Spain \\ ${ }^{3}$ Department of Agricultural, Food \& Nutritional Sciences, University of Alberta, Edmonton, AB, Canada T6G 2P5 \\ ${ }^{4}$ Dipartimento di Ingegneria Chimica, Gestionale, Informatica, Meccanica, Università di Palermo, 90128 Palermo, Italy
}

Correspondence should be addressed to Giuseppe Caputo; gcaputo@unisa.it

Received 25 July 2013; Accepted 25 July 2013

Copyright ( 2013 Giuseppe Caputo et al. This is an open access article distributed under the Creative Commons Attribution License, which permits unrestricted use, distribution, and reproduction in any medium, provided the original work is properly cited.

Supercritical fluids (SCFs) are unconventional solvents exhibiting tunable physicochemical properties that make them highly interesting to perform both physical processing and chemical reactions.

Most of the processes based on SCFs take advantage of the near-critical region where substances exhibit gas-like transport properties (viscosity, diffusivity), but they can assume densities from gas-like to liquid-like values depending on the pressure. For this reason, SCFs are sometimes known as "variable geometry" solvents. This unique property, coupled with the environmentally friendly characteristics of some common SCFs make them attractive for a large variety of processes. Most of the investigations are performed using supercritical carbon dioxide $\left(\mathrm{SC}-\mathrm{CO}_{2}\right)$ that cumulates tunability of thermodynamic and transport properties with favourable technoeconomical features such as wide availability and low cost, biocompatibility, and mild critical parameters.

During the last four decades, extensive research has been carried out worldwide about a large variety of applications of SCFs. Some fields have been abandoned while others have been developed up to industrial production. It is relevant to highlight that supercritical fluids utilization covers broad amplitude of applications, and new applications are very often proposed in the scientific literature.

An important research theme that is going to be object of growing interest and is not covered in this issue is the study of thermal or thermocatalytic processes in near/supercritical water to convert biomasses into fuels and/or chemicals. The topic is located in the context of biorefinery, and the interest in its development is stimulated by the fact that using as solvent compressed water in near-critical or supercritical conditions it is possible to work with wet biomasses limiting energetic penalty associated with latent heat of water vaporization and having access to operating conditions in which permanent gases, such as hydrogen, are fully miscible with the solvent, and transport properties of the reaction medium are similar to those of a gas with consequent intensification of mass transfer rate controlled steps. Examples of the researches developed in this field are the gasification of lignocellulosic biomasses in supercritical water [1-3] and the liquefaction of aquatic biomass [4]. Other emerging and sound technologies for industrial applications include spray processing for micro-/nanoparticles production [5-7], adsorption of drugs on silica aerogels [8-10], production of biocompatible biodegradable polymers for drug release by supercritical technology $[11,12]$, recycling polymer wastes by dissolution and $\mathrm{SC}-\mathrm{CO}_{2}$ technology [13], supercritical impregnation of bioactive lipids [14], the formation of SC$\mathrm{CO}_{2}$ dried aerogels $[15,16]$, and enzymatic reactions in SC$\mathrm{CO}_{2}$ media [17-19].

In addition to these themes, this special issue was developed to give the reader an overview of some possible utilizations of supercritical fluids. The special issue contains six papers, of which two are related to the utilization of supercritical fluids in biomedical application for the preparation 
of polymeric drug carriers or drug-cyclodextrins inclusion complexes.

Two articles cover the topic of supercritical fluid assisted modification of polymer based matrixes to obtain controlled foaming of poly(methyl methacrylate)/silica nanocomposites or polymer fibers by electrospinning. One is devoted to the utilization of supercritical carbon dioxide to perform mild temperature pasteurization of food liquids, and one reports the extraction of oil fractions from complex biomass matrixes.

"Controlling foam morphology of poly(methyl methacrylate) via surface chemistry and concentration of silica nanoparticles and supercritical carbon dioxide process parameters" by D. Rende et al. studies the effects of surface modification in the polymer nanocomposite foam morphology, as well as the treatment with supercritical $\mathrm{CO}_{2}$ to obtain low average size cells improving the density and therefore their mechanical properties. The surface modification of silica nanoparticles with $\mathrm{CO}_{2}$-philic surfactants has the strongest effect on foam morphology.

"Characterization of ketoprofen/methyl- $\beta$-cyclodextrin complexes prepared using supercritical carbon dioxide" by $\mathrm{M}$. Banchero et al. describes the encapsulation of ketoprofen in methyl- $\beta$-cyclodextrin by a supercritical impregnation method, to obtain complexes with enhanced release kinetics. The study is focused on the characterization of the product by several techniques (DSC/XRD/FTIR structural analyses and in vitro drug release tests).

"Producing polymer fibers by electrospinning in supercritical fluids" by L. Li et al. reviews a new process where electrospinning is conducted in supercritical or near-critical $\mathrm{CO}_{2}$ to produce porous or hollow nanofibers. Moreover, authors discuss the reason why a compressed $\mathrm{N}_{2}$-assisted electrospinning is unsuccessful.

In the field of supercritical fluid extraction a paper is presented entitled "Quality of cosmetic argan oil extracted by supercritical fluid extraction from Argania spinosa L." by C. Taribak et al. This paper evaluates the influence of pressure and temperature for the supercritical $\mathrm{CO}_{2}$ extraction of argan oil. Furthermore, the argan oil extracts were characterized based on their bioactive compounds contents as well as their antioxidant capacity for possible cosmetic applications.

In the area of pasteurization, a paper entitled "Quality attributes of fresh-cut coconut after supercritical carbon dioxide pasteurization" by G. Ferrentino et al. is part of this especial edition. In this contribution, the impact of supercritical $\mathrm{CO}_{2}$ technology on the quality attributes of fresh-cut coconut in terms of quality was investigated at optimal pasteurization conditions that allows the maximum reduction of coconut microbial content. The results showed effects on coconut attributes, such as color, $\mathrm{pH}$, fat content, enzyme activity, total phenols, flavonoids, antioxidant capacity, enzyme activity, and sensory attributes (aroma, taste, appearance, and texture).

In the area of particle formation, an important contribution entitled "Supercritical assisted atomization: polyvinylpyrrolidone as carrier for drugs with poor solubility in water" by S. Liparoti et al. was discussed. In this contribution, supercritical assisted atomization was used to produce microparticles of polyvinylpyrrolidone as carrier for dexamethasone, an important pharmaceutical compound with poor solubility in water, allowing high dissolution rate. Microparticles produced with $0.8-1 \mu \mathrm{m}$ of diameter in this study showed regular and spherical shape, depending on the polyvinylpyrrolidone/dexamethasone weight ratio. This carrier can be further used with other drugs of poor solubility in water.

Of course, these topics and papers are not a comprehensive representation of the area of this special issue. Nonetheless, they represent the rich and many-faceted knowledge that we have the pleasure of sharing with the readers.

\section{Giuseppe Caputo Ignacio Gracia Fernández Marleny D. A. Saldaña Alessandro Galia}

\section{References}

[1] A. Kruse, "Supercritical water gasification," Biofuels, Bioproducts and Biorefining, vol. 2, no. 5, pp. 415-437, 2008.

[2] D. C. Elliott, "Catalytic hydrothermal gasification of biomass," Biofuels, Bioproducts and Biorefining, vol. 2, no. 3, pp. 254-265, 2008.

[3] G. Brunner, "Near critical and supercritical water. Part I. Hydrolytic and hydrothermal processes," Journal of Supercritical Fluids, vol. 47, no. 3, pp. 373-381, 2009.

[4] T. M. Yeh, J. G. Dickinson, A. Franck, S. Linic, L. T. Thompson, and P. E. Savage, "Hydrothermal catalytic production of fuels and chemicals from aquatic biomass," Journal of Chemical Technology and Biotechnology, vol. 88, no. 1, pp. 13-24, 2013.

[5] G. Caputo, R. Adami, and E. Reverchon, "Analysis of dissolvedgas atomization: supercritical $\mathrm{CO}_{2}$ dissolved in water," Industrial and Engineering Chemistry Research, vol. 49, no. 19, pp. 9454-9461, 2010.

[6] G. Caputo, S. Liparoti, R. Adami, and E. Reverchon, "Use of supercritical $\mathrm{CO}_{2}$ and $\mathrm{N}_{2}$ as dissolved gases for the atomization of ethanol and water," Industrial \& Engineering Chemistry Research, vol. 51, no. 36, pp. 11803-11808, 2012.

[7] E. Reverchon, G. Caputo, S. Correra, and P. Cesti, "Synthesis of titanium hydroxide nanoparticles in supercritical carbon dioxide on the pilot scale," The Journal of Supercritical Fluids, vol. 26, no. 3, pp. 253-261, 2003.

[8] I. Smirnova, J. Mamic, and W. Arlt, "Adsorption of drugs on silica aerogels," Langmuir, vol. 19, no. 20, pp. 8521-8525, 2003.

[9] G. Caputo, I. de Marco, and E. Reverchon, "Silica aerogel-metal composites produced by supercritical adsorption," Journal of Supercritical Fluids, vol. 54, no. 2, pp. 243-249, 2010.

[10] G. Caputo, M. Scognamiglio, and I. de Marco, "Nimesulide adsorbed on silica aerogel using supercritical carbon dioxide," Chemical Engineering Research and Design, vol. 90, no. 8, pp. 1082-1089, 2012.

[11] L. I. Cabezas, V. Fernández, R. Mazarro, I. Gracia, A. de Lucas, and J. F. Rodríguez, "Production of biodegradable porous scaffolds impregnated with indomethacin in supercritical $\mathrm{CO}_{2}$," Journal of Supercritical Fluids, vol. 63, pp. 155-160, 2012.

[12] L. I. Cabezas, I. Gracia, M. T. García, A. de Lucas, and J. F. Rodríguez, "Production of biodegradable porous scaffolds impregnated with 5-fluorouracil in supercritical $\mathrm{CO}_{2}$," Journal of Supercritical Fluids, vol. 80, pp. 1-8, 2013. 
[13] C. Gutiérrez, M. T. García, I. Gracia, A. de Lucas, and J. F. Rodríguez, "The selective dissolution technique as initial step for polystyrene recycling," Waste and Biomass Valorization, vol. 4, no. 1, pp. 29-36, 2013.

[14] L. M. Comin, F. Temelli, and M. D. A. Saldaña, "Impregnation of flax oil in pregelatinized corn starch using supercritical $\mathrm{CO}_{2}$," Journal of Supercritical Fluids, vol. 61, pp. 221-228, 2012.

[15] L. M. Comin, F. Temelli, and M. D. A. Saldaña, "Barley $\beta$-glucan aerogels as a carrier for flax oil via supercritical $\mathrm{CO}_{2}$," Journal of Food Engineering, vol. 111, no. 4, pp. 625-631, 2012.

[16] L. Comin, F. Temelli, and M. D. A. Saldaña, "Barley $\beta$ glucan aerogels via supercritical $\mathrm{CO}_{2}$ drying," Food Research International, vol. 48, pp. 442-448, 2012.

[17] D. Ciftci and M. D. A. Saldaña, "Enzymatic synthesis of phenolic lipids using flax oil and ferulic acid in supercritical carbon dioxide media," The Journal of Supercritical Fluids, vol. 72, pp. 255-262, 2012.

[18] G. H. C. Prado, M. Khan, M. D. A. Saldaña, and F. Temelli, "Enzymatic hydrolysis of conjugated linoleic acid-enriched anhydrous milk fat in supercritical carbon dioxide," Journal of Supercritical Fluids, vol. 66, pp. 198-206, 2012.

[19] G. H. C. Prado and M. D. A. Saldaña, "Optimization of enzymatic hydrolysis of sacha inchi oil using conventional and supercritical carbon dioxide processes," Journal of the American Oil Chemists' Society, vol. 90, no. 5, pp. 731-742, 2013. 

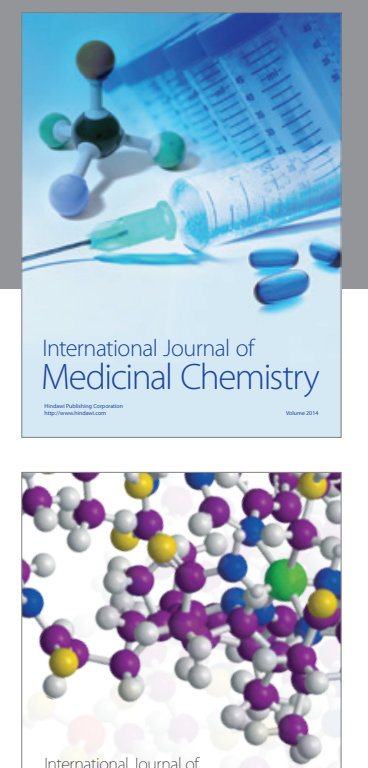

\section{Carbohydrate} Chemistry

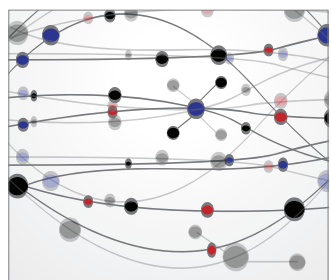

The Scientific World Journal
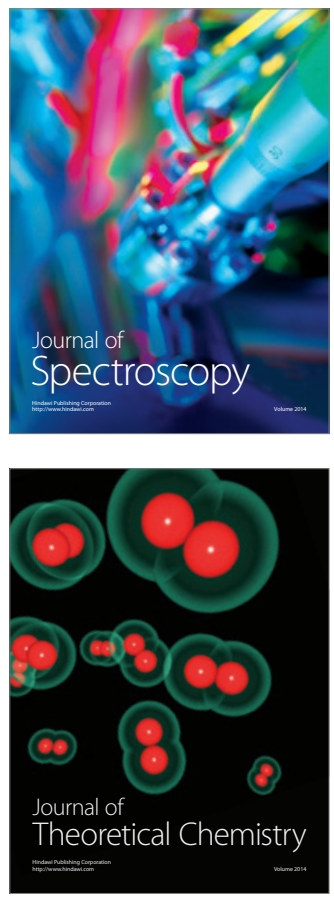
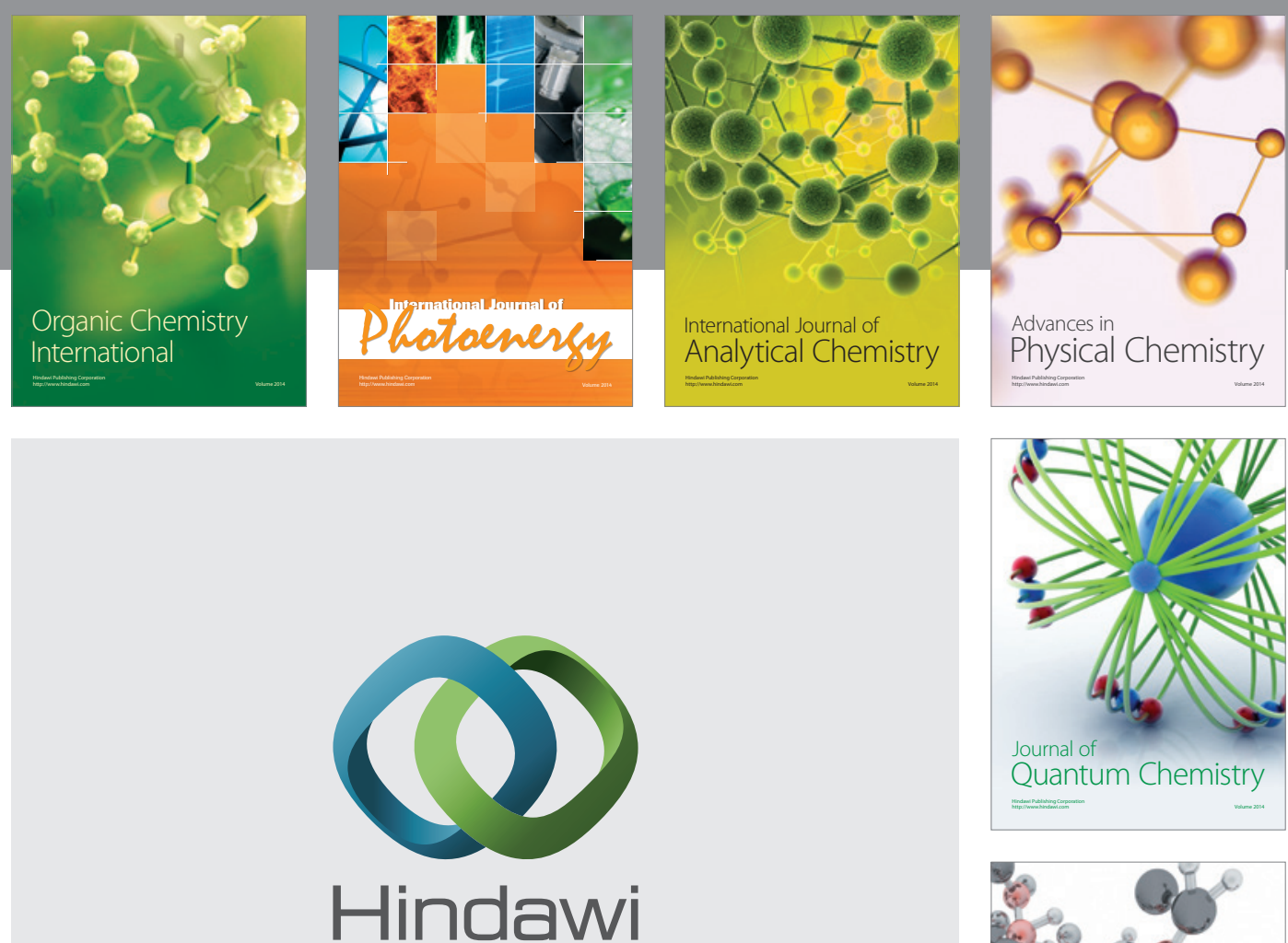

Submit your manuscripts at

http://www.hindawi.com

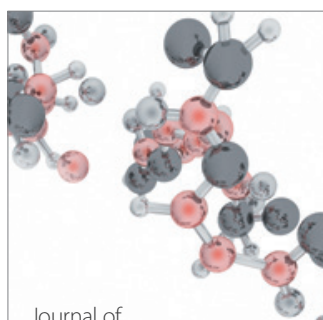

Analytical Methods

in Chemistry

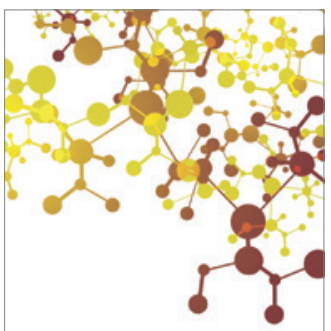

Journal of

Applied Chemistry

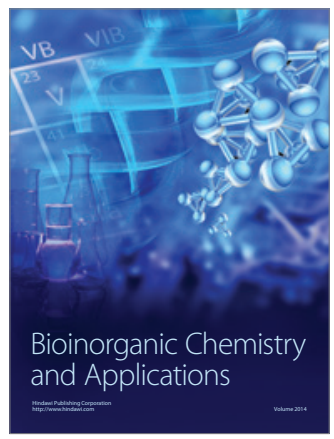

Inorganic Chemistry
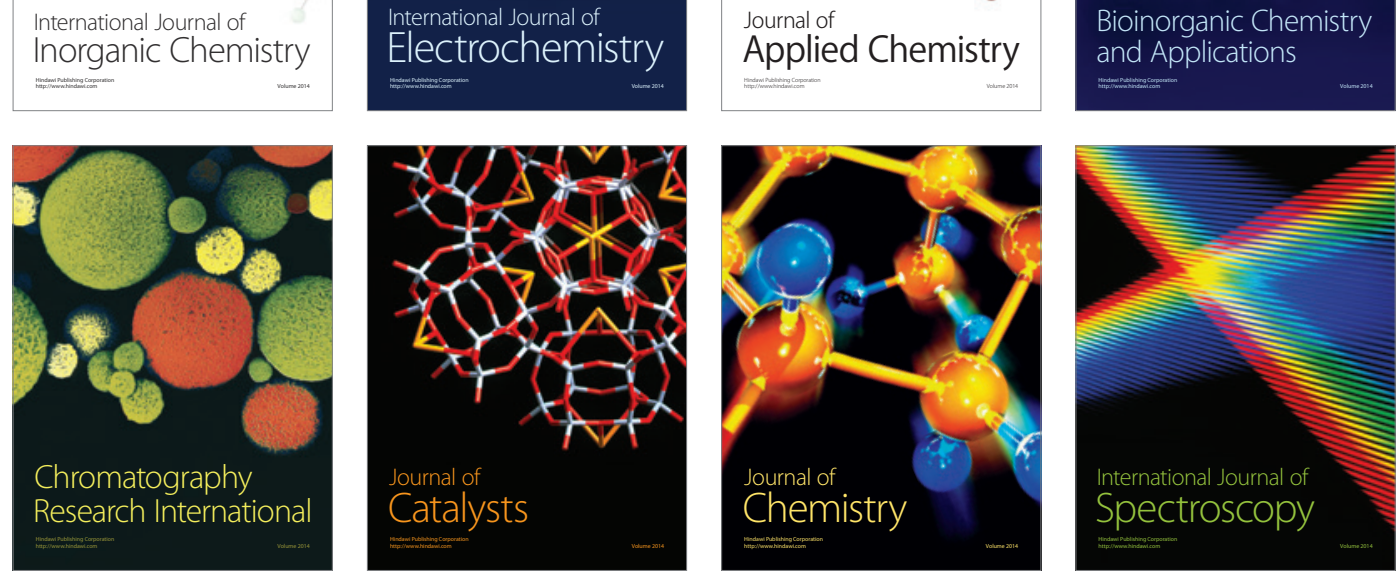